Majalah Bulanan

Rp 15.000:-

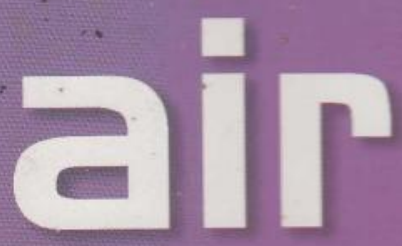

€disi I73 februari 2010

ISSN OI26-2785
Persatuan
Perusahaan Air Minum
Seluruh Indonesia

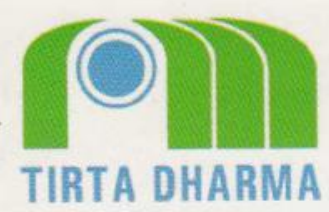






\section{Rotating Biological Contactor}

Adaptasi unik. Inilah sebutan yang diberikan kepada Rotating Biological Contactor (RBC) karena modifikasinya khas sebagai proses pertumbuhan lekat (attached growth process).

Sesuai dengan namanya, unit pengolah air limbah ini berotasi dengan pusat pada sumbu atau

as yang digerakkan oleh motor drive system dan/atau tiupan udara (air drive system) dari difusser yang dibenam dalam air limbah, di bawah media. Berbahan plastik, media tempat pelekatan mikroba dipasang sedemikian rupa sehingga terjadi kontak yang seluasluasnya dengan air limbah dan oksigen yang terjadi silih berganti.

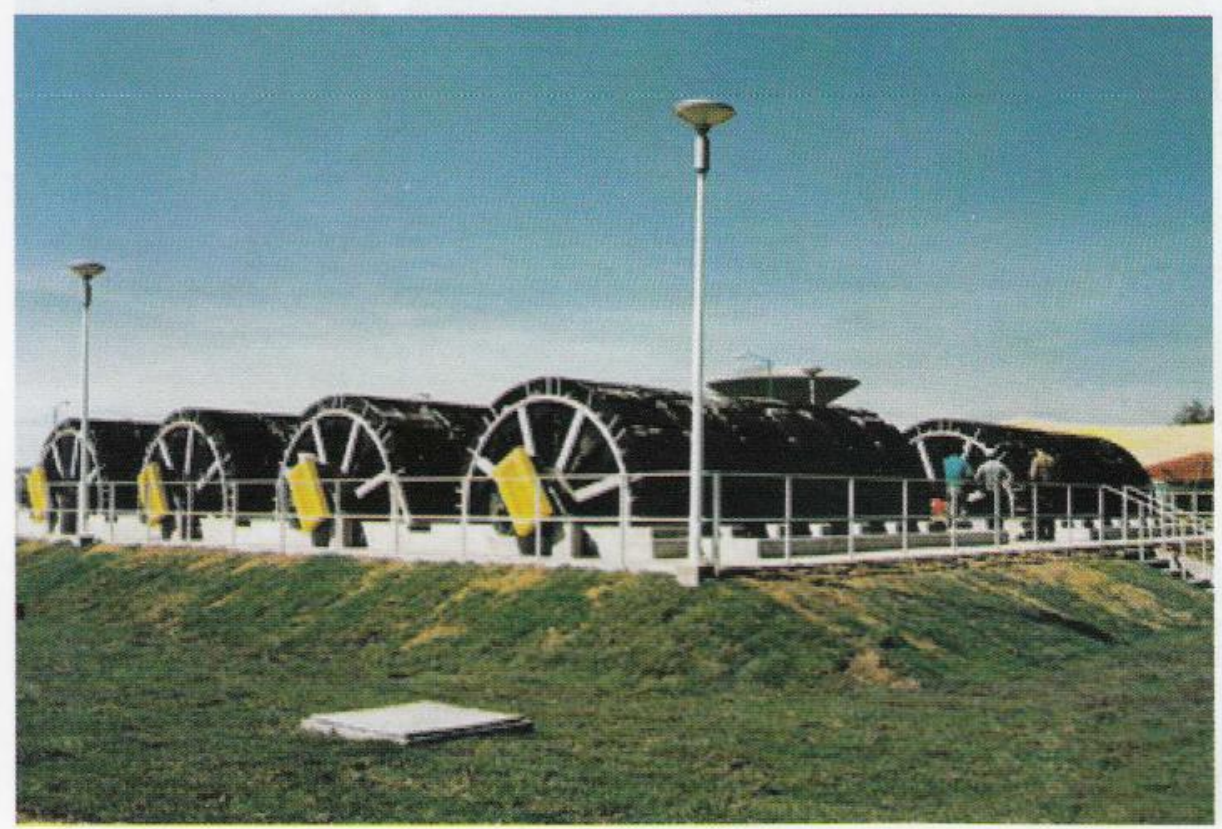

\section{oleh Gede H. Cahyana}

http://gedehace.blogspot.com

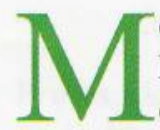
ekanisme aerasinya terjadi ketika mikroba terpapar oksigen di luar air limbah sehingga terjadi pelarutan oksigen akibat difusi. Sesaat kemudian, mikroba ini tercelup lagi ke dalam air limbah sekaligus memberikan oksigen kepada mikroba yang tersuspensi di dalam bak. Bersamaan dengan itu terjadi juga reintake material organik dan anorganik yang melekat di dalam biofilm. Tetesan air berbutir-butir yang jatuh dari media plastik dan bagian biofilm yang melekat di permukaan plastik juga memberikan peluang reaerasi. Begitu seterusnya secara kontinyu 24 jam sehari, ada bagian yang terendam air, ada bagian yang terpapar oksigen.

Historisnya, meskipun RBC telah dikenal pada dekade 1920-an di Jerman 
terhadap beban kejut (shock looading) organik dan hidrolis, peluruhan biomassa berlebihnya efektif. Konsumsi atau kebutuhan energi listriknya juga rendah dibandingkan dengan aerasi mekanis pada activated sludge dan trickling filter. RBC juga mampu mengolah air limbah timbulan aktivitas pertambangan yang mengandung senyawa beracun, besi, sianida, selenium, dan lain-lain.

Selain keunggulan, kekurangannya juga ada. Masalah utama RBC adalah kerusakan pada materialnya seperti as, coupling, bearing, rantai, gear box, motor listrik, dll. Biaya kapital dan pemasangan RBC bisa lebih mahal daripada activated sludge per debit per kualitas air limbah yang setara. Secara bioproses, kalau oksigen terlarutnya rendah dan ada sulfida di dalam air limbahnya maka bakteri pengganggu seperti Beggiatoa akan tumbuh di media RBC. Dibandingkan dengan unit lumpur aktif konvensional, biaya investasi RBC menjadi mahal kalau debit air olahannya besar. Oleh sebab itu, RBC lebih cocok diterapkan pada debit kecil, misalnya untuk air limbah rumah sakit, hotel, pabrik, kampus. Dalam desainnya, meskipun sudah banyak diteliti, belum banyak terungkap parameter desain yang berkaitan dengan bioproses kecuali rumus-rumus empiris. Itu sebabnya, desainer RBC selalu menggunakan tabel dan grafik yang dibuat oleh praktisi dan didasarkan pada parameter dari instalasi yang sudah dibangun.

Kinerja RBC bergantung juga pada jumlah kompartemennya. Satu modul bisa berisi empat atau lima kompartemen. $\mathrm{Di}$ kompartemen pertama bisa ditambahkan aliran balik menuju unit pengendap awal agar kondisinya tidak terlalu anaerobik sehingga bau busuknya berkurang sekaligus membantu dinamika pertumbuhan mikroba. Begitu juga di kompartemen akhir bisa dipasang aliran balik menuju unit pengendap awal dengan maksud serupa. Umumnya, media kontak RBC terendam di dalam air limbah setinggi $40 \%$ dari diameternya. Kecepatan putarannya antara $1-3$ putaran per menit. Putaran ini memberikan energi yang cukup bagi gaya hidrolis untuk meluruhkan biofilm dan aliran airnya turbulen supaya padatannya tetap tersuspensi (tidak mengendap).
Waktu tinggal hidrolisnya di dalam setiap modul relatif singkat, yaitu 20 menit pada beban normal. Setiap tahap atau modulnya cenderung beroperasi sebagai reaktor teraduk sempurna.

Berkaitan dengan media lekat mikrobanya, ada beberapa bahan yang dapat digunakan. Yang sering dipilih adalah media plastik HDPE (high-density polyethylene) berdiameter antara $2-4$ $\mathrm{m}$, dengan ketebalan mencapai $10 \mathrm{~mm}$. Bentuk media bisa berupa lembaran pelat tetapi bisa juga berupa pipa-pipa atau tabung yang dipasang pada satu poros besi dengan bentangan mencapai $8 \mathrm{~m}$. Media beserta poros dan motornya ini disebut satu modul yang terus berotasi di dalam bak. Beberapa modul dapat dipasang secara seri atau paralel sesuai dengan kebutuhan debit air limbah yang diolah. Biasanya antarmodul dipisahkan oleh sekat (baffle) untuk menghindari aliran singkat (short

RBC menjadi salah satu alternatif teknologi yang akan makin banyak diterapkan, terutama untuk populasi kecil seperti hotel, apartemen, rumah sakit, pabrik, kantor, dan kampus.

circuiting) di dalam tangki (bak). Kinerja RBC pun dipengaruhi oleh temperatur air limbah, konsentrasi substrat influen, waktu tinggal hidrolis, rasio volume tangki terhadap luas permukaan media, kecepatan rotasi media, dan oksigen terlarut.

\section{Deskripsi Proses}

Umumnya, untuk mengolah air limbah domestik RBC tidak memerlukan pembibitan (seeding) mikroba. Sebab, mikroba sudah tersedia dalam jumlah yang cukup sebagai awal dalam memulai proses. Kira-kira sepekan sampai dua pekan setelah dimulai pengolahannya, di permukaan media akan menempel biomassa setebal $1-4 \mathrm{~mm}$. Ketebalan ini bergantung pada kekuatan air limbah dan kecepatan rotasi media lekat. Menurut Antonie, 1978, konsentrasi mikroba tersebut mencapai $50.000-100.000 \mathrm{mg} / \mathrm{l}$, suatu jumlah yang sangat tinggi sehingga cukup banyak zat pencemar organik dan nitrogen yang dihilangkannya dengan bantuan oksigen terlarut.

Seperti umumnya pengolahan air limbah secara biologi, RBC merupakan bioproses "peternakan" mikroba (bakteri). Jenis-jenis mikroba yang biasa ditemukan di RBC ialah bakteri berfilamen seperti Sphaerotilus, Beggiatoa, Cladothrix, Nocardia, Oscillatoria, dan juga jenis fungi, yaitu Fusarium, meskipun jarang. Mikroba yang nonfilamen antara lain: Zocloea, Aerobacter, Escherichia coli, algae, dan spirilla. Jenis dan konsentrasi mikroba bisa berbeda antara satu modul dengan modul lainnya dan ini dipengaruhi oleh beban organiknya. Semua mikroba di atas bahu-membahu mengolah pencemar organik di dalam air limbah dengan cara mengoksidasinya dalam kondisi aerob. Dalam kondisi normal, senyawa polutan berbasis karbon akan disisihkan lebih dulu di modul satu RBC. Penyisihan karbon bisa tuntas di modul satu atau modul dua ini tetapi proses nitrifikasi baru selesai di modul lima atau sesudahnya. Seperti pada proses di dalam bio-tower, nitrifikasi akan terjadi hanya setelăh konsentrasi karbon direduksi secara signifikan. Oleh sebab itu, kebanyakan RBC terdiri atas empat atau lima modul seri untuk memberikan kesempatan proses nitrifikasi terjadi secara lengkap. Setelah lewat RBC, air limbah lantas masuk ke klarifir dan biomassa mulai mengendap secara gravitasi.

Klarifir dalam sistem RBC ini tidak menyalurkan sludge endapannya ke RBC seperti yang terjadi pada activated sludge. Efluen klarifirnya sudah bisa langsung dibuang ke badan air penerima tanpa perlu diklorinasi. Apabila efluen ini akan digunakan kembali maka perlu dilengkapi dengan teknologi pengolahan air minum pada umumnya (seperti yang sering diterapkan di PDAM) ditambah dengan unit karbon aktif dan teknologi membran. Dengan demikian, RBC menjadi salah satu alternatif teknologi yang akan makin banyak diterapkan, terutama untuk populasi kecil seperti hotel, apartemen, rumah sakit, pabrik, kantor, dan kampus, sekaligus mendukung konsep desentralisasi dalam pengolahan air limbah atau semacam "on-site system", bukan sistem perpipaan (sewerage). 